\title{
Os desdobramentos do Pacto Nacional pelo Fortalecimento do Ensino Médio nas ações educativas da Escola Sales Campos
}

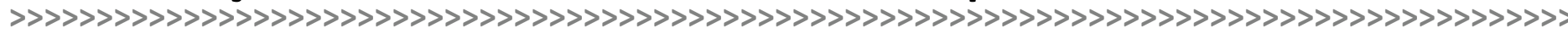

\section{Resumo:}

O presente texto apresenta uma reflexão sobre a execução da primeira etapa do programa de formação continuada dos professores do Ensino Médio denominado Pacto Nacional pelo Fortalecimento do Ensino Médio (PNEM) e os resultados que o referido programa gerou na prática educativa dos professores participantes na Escola Estadual de Ensino Fundamental e Médio Sales Campos, localizada em Fortaleza - Ceará, na qual atuei como Orientadora de Estudos (OE) durante o intervalo de abril a dezembro de 2014, que corresponde ao período de realização da primeira etapa do PNEM no Ceará. Ao longo do processo formativo uma infinidade de discussões e atividades foram realizadas. Deparamo-nos com entendimentos, desentendimentos, construções, desconstruções, barreiras a serem superadas, aprendizado e diversas oportunidades de pensar e repensar nossa prática educativa na Escola.

\section{Palavras-chave:}

Formação Continuada. Prática Educativa. Pacto pelo Fortalecimento do Ensino Médio.

\begin{abstract}
:
This paper presents a reflection on the implementation of the first stage of the continuing education program for high school teachers called the National Pact for Secondary Education Strengthening (PNEM) and the results that the program generated in the educational practice of teachers participating in the State School of Elementary and Secondary Education Sales Campos, located in Fortaleza - Ceará, in which I worked as a Guidance Studies (OE) during the period April to December 2014, which corresponds to the duration of the first stage of PNEM in Ceará. Throughout the training process a multitude of discussions and activities were generated. We face understandings, misunderstandings, constructions, deconstructions, barriers to be overcome, learning and many opportunities to think and rethink our educational practice at school.
\end{abstract}

\section{Keywords:}

Continuing education. Educational practice. Pact for Secondary Education Strengthening.

\section{Introdução}

O Pacto Nacional pelo Fortalecimento do Ensino Médio (PNEM), instituído pela Portaria n.o 1.140, de 22 de novembro de 2013, é um programa de formação continuada de professores do Ensino Médio, operacionalizado pelo Ministério da Educação (MEC),

* > Mestre em História. Professora da Disciplina de História da rede de ensino da Secretaria da Educação do Ceará (SEDUC/CE).E-mail: hisllya@gmail.com 
que teve suas duas etapas executadas entre março de 2014 a dezembro de $2015 \mathrm{em}$ todo o pais. De acordo com essa portaria do MEC, o PNEM

[...] representa a articulação e a coordenação de ações e estratégias entre a União e os governos estaduais e distrital na formulação e implantação de políticas para elevar

Nesse sentido, a formação continuada no âmbito do PNEM teve como propósito principal promover a valorização da formação continuada dos professores e coordenadores pedagógicos que atuam no Ensino Médio público, em consonância com a Lei Diretrizes e Bases da Educação Nacional (LDB), as Diretrizes Curriculares Nacionais do Ensino Médio (DCNEM) e o Plano Nacional de Educação (2014-2024).

No Ceará, o PNEM ficou sob a responsabilidade da Universidade Federal do Ceará (UFC) e da Secretaria da Educação (SEDUC/CE) e apresentava os seguintes objetivos: Contribuir para o aperfeiçoamento da formação dos professores e coordenadores pedagógicos do ensino médio; Promover a valorização pela formação dos professores coordenadores pedagógicos do ensino médio: Rediscutir e atualizar as príticas docentes em conformidade com as DCNEM; Promover a valorização do professor da rede pública estadual do Ensino Médio através da oferta de formação continuada e Refletir sobre currículo do Ensino Médio, promovendo o desenvolvimento de práticas educativas efetivas com foco na formação humana integral, conforme apontado nas DCNEM. E as seguintes metas: Superar as metas estabelecidas para o IDEB e PISA; Melhorar indicadores de Fluxo no Ensino Médio; Melhorar indicadores de proficiência em Português, Matemática Ciências e Avaliação censitária do Ensino Médio com resultados por rede e município.

Uma das premissas fundamentais do Pacto, presente na Resolução n. ${ }^{\circ}$ 51, de 11 de dezembro de 2013, foi a instituição da escola como lócus para o desenvolvimento da formação pautada no diálogo com as políticas públicas para o Ensino Médio; como orientadora dos projetos políticos pedagógicos e dos currículos escolares, seus formatos, tempos e espaços; e como o ambiente gerador da reflexão crítica e das mudanças decorrentes dessa reflexão, sendo, também, beneficiária dos resultados construidosa partir das práticas coletivas fundamentadas nessas mesmas reflexões. Assim, pensando e repesando a Escola na Escola, buscava-se garantir o envolvimento dos professores numa discussão qualificada, de caráter formativo e permanente, visando a melhoria da qualidade da educação e a efetiva implementação das DCNEM, que aponta o trabalho, a cultura, a ciência e a tecnologia como dimensões que devem estar contempladas nos currículos do Ensino Médio, integrando os conhecimentos das diferentes áreas de ensino.

O processo formativo apresentava como eixo estruturante a temática "Sujeitos do Ensino Médio e Formação Humana Integral", sendo este o seu fio condutor, subdividido em seis campos temáticos: Ensino Médio e Formação Humana Integral; O Jovem como Sujeito do Ensino Médio; Currículo do Ensino Médio; Áreas de Conhecimento e Integração Curricular; Organização e Gestão do Trabalho Pedagógico e Avaliação no Ensino Médio.

Cada um desses campos temáticos tinha como material de apoio um caderno elaborado pelo MEC, que subsidiava as discussões e atividades a serem desenvolvida pelos professores cursistas. Todo o processo de formação era mediado na Escola pelo Orientador de Estudos, que a planejava com a mediação do Formador Regional. Esses campos temáticos foram pensados a partir das DCNEM e orientavam a reflexão coletiva sobre a prática docente e a importância da participação de todos os atores do processo educativo na construção e efetivação do Projeto Político Pedagógico da escola (PPP) e, consequentemente, orientavam o (re)desenho do currículo do Ensino Médio, apoiando e fortalecendo o desenvolvimento de propostas curriculares inovadoras, integradas, inter e transdisciplinares na escola, buscando garantir a formação integral com a inserção de atividades que tornassem o currículo mais dinâmico, mais próximo da realidade do educando, atendendo as suas expectativas e às demandas das juventudes e sociedade contemporâneas, além de possibilitar uma reflexão específica sobre as diversidades no sentido de garantir os direitos de aprendizagem e de desenvolvimento para todos os educandos.

De acordo com o documento orientador das ações de formação continuada de professores e coordenadores pedagógicos do Ensino Médio em 2014, “[...] a proposta do curso compreende o professor como um sujeito epistêmico, que elabora e produz conhecimentos com base na compreensão da realidade e nas possibilidades de transformação da sociedade" (BRASIL, 2014a). Nesse sentido, a formação continuada dos professores do Ensino Médio deve lhe permitir atuar no Ensino Médio de modo a materializar os pressupostos e fundamentos das DCNEM, aprofundando sua consistência teórica e qualificando-se para o desenvolvimento de uma prática que atenda as demandas dos estudantes e da sociedade a partir do desenvolvimento de um currículo orientado a partir dessas Diretrizes e deve ser sustentada, conforme enuncia Kuenzer (2011), nos seguintes eixos:

" contextual, articulando os conhecimentos sobre educação, economia, política e sociedade, e suas relações, tomadas em seu desenvolvimento histórico;

" epistemológico, integrando as teorias e princípios que regem a produção social do conhecimento

" institucional, contemplando as formas de organização dos espaços e processos educativos escolares e não escolares

" pedagógico, integrando os conhecimentos relativos a teorias e práticas pedagógicas, gerais e específicas, incluindo cognição, aprendizagem e desenvolvimento humano;

práxico, de modo a integrar conhecimento científico, conhecimento tácito e pratica social;

" ético, compreendendo as finalidades e responsabilidades sociais e individuais no campo da educação, em sua relação com a construção de relações sociais e produtivas, segundo os princípios da solidariedade, da democracia e da justiça social;

" investigativo, comprometido com o desenvolvimento das competências em pesquisa, tendo em vista o avanço conceitual na área do trabalho e da educação.

Diante dessa proposta de formação continuada do PNEM, que nos foi apresentada pela coordenação geral do programa no Ceará - UFC e pelos formadores regionais SEDUC/CE, iniciamos em abril de 2014 a trajetória formativa dos docentes do Ensino Médio da Escola Estadual de Ensino Fundamental e Médio Sales Campos.

\section{Percurso Formativo}

O processo de construção da operacionalização do PNEM na Escola Sales Campos iniciou-se em abril (08/04/2014) quando, em assembleia, os professores da Escola reuniramse para a escolha do orientador de estudos (OE), ocasião na qual fui escolhida para essa função. Em junho (05/06/14), tivemos o primeiro encontro com os formadores regionais e, a partir de então, começamos a visualizar com mais clareza o que era, o que significava como deveria ser executado o PNEM.

No mês de agosto, chegamos ao momento de efetivar as ações do PNEM na Escola. Logo após o segundo encontro com os formadores regionais, ocorrido no dia 08/08/14 iniciamos a preparação dos encontros formativos na Escola. A segunda semana de agosto (11 a 15/08/14) foi dedicada a essa preparação. Foi o momento de definirmos junto à coordenação da Escola e aos professores os horários do curso, quantas turmas teríamos, de redefinir os horários dos professores em sala de aula para que todos pudessem participar das formações sem nenhum prejuízo para os alunos, de elaborarmos um cronograma de 
trabalho, estabelecermos em que espaço físico as formaçōes aconteceriam, conferirmos os professores bolsistas e listarmos os que iriam participar do curso sem bolsa, entre outros ajustes.

É importante ressaltar que a direção e a coordenação da Escola apoiaram totalmente, desde o início, a realização e viabilização do curso e que contamos com o envolvimento e participação de todos os professores do Ensino médio lotados na Escola, tanto os que tinham direito ao recebimento da bolsa, como os que não tinham.

No final dessa semana estabelecemos o seguinte: os encontros formativos aconteceriam nos dias dos planejamentos por área do conhecimento, na sala da coordenação da Escola, nas três primeiras aulas do turno da manhã. Sendo assim, foram formadas três turmas - uma na terça-feira para os professores das Linguagens, da qual participavam seis docentes; outra na quarta-feira para os professores das Ciências da Natureza e Matemática, com sete cursistas; e outra na quinta-feira para os professores das Ciências Humanas, que contava com seis professores participantes. Dessa forma, todos os professores foram contemplados com o processo formativo.

Ao todo tínhamos 12 professores inscritos no Sistema Integrado de Monitoramento, Execução e Controle (SIMEC/SisMédio), ou seja, que teriam direito ao recebimento de uma bolsa de estudos no valor de $\mathrm{R} \$ 200,00$ para participarem da formação, e seis professores não bolsistas, que aderiram ao curso, mesmo impossibilitados de receberem essa bolsa de estudos. Dois professores cadastrados no SIMEC em turmas de outra Escola, ma que também atuavam como docentes na nossa, participaram das formações conosco. $O$ contato com suas orientadoras de estudo era mantido por e-mail e/ou telefone, sempre que necessário.

Ao todo, foram 21 semanas de desenvolvimento das atividades da primeira etapa do PNEM na Escola, 17 encontros formativos com cada turma e uma infinidade de discussões, atividades, entendimentos, desentendimentos, construções, desconstruções, barreiras vencidas, aprendizado, oportunidades de pensar e repensar nossa prática educativa na Escola Sales Campos. Durante esse percurso, escrevi um "Diário de bordo do Pacto", no qual registrei quando, como e com quem foram realizadas todas as atividades e algumas impress̃̃es

Durante esses 17 encontros formativos que usufruímos com cada turma, tivemo a oportunidade de trabalhar as seguintes temáticas: 1. Apresentação do PNEM; 2. Ensino Médio e Formação Humana Integral; 3. Aprendizagem Cooperativa; 4 . O jovem como sujeito do Ensino Médio; 5. Educação Integral; 6. Diretrizes curriculares e projetos pedagógicos; 7. Indicadores e Avaliações educacionais; 8. Jovens, culturas, espiritualidade, identidades e tecnologias; 9. Fundamentos curriculares do Ensino Médio; 10. Ação curricular integrada; 11. Áreas do conhecimento, currículo e Ensino Médio integrado; 12. Aproximação do conhecimento das diferentes áreas; 13. ENEM: Desafios e possibilidades de integração curricular; 14. Gestão democrática da Escola; 15. Avaliação no Ensino Médio.

Durante esses 10 meses (de abril de 2014 até a primeira semana de março de 2015) tive o privilégio e a responsabilidade de, como orientadora de estudos (OE), estar imers no universo do PNEM. Desde minha escolha como OE da Escola em abril, passando pela primeira formação com os formadores regionais (FR) em junho e o início efetivo das atividades na Escola em agosto de 2014, até a primeira semana de março de 2015, que foi a última de formação da primeira etapa na nossa Escola, muitas foram as experiência vividas, as atividades realizadas, as oportunidades adquiridas e aproveitadas, os projetos pensados e elaborados e o aprendizado construido. Durante esse processo formativo, pudemos pensar, repensar, elaborar e reelaborar muita coisa na Escola Sales Campos.

Alguns temas geraram desconforto, outros eram novidades em nosso meio, alguns já eram discutidos e objeto de reflexão e prática entre nós. O interessante é que as temáticas trabalhadas, os encontros realizados, as discussões ocasionadas serviram para provocar, para gerar questionamentos, estranhamentos e inquietações quanto ao nosso papel como professor e o papel do nosso aluno na construção de um Ensino Médio de qualidade e efetivamente comprometido com a formação humana integral dos nossos educandos.

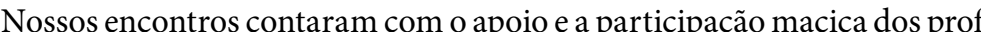

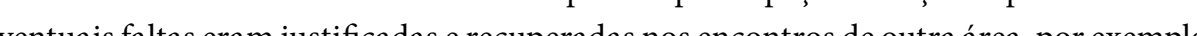
O interesse e envolvimento dos professores foram genuínos do início ao fim da primeira etapa, realizando prontamente tudo que era solicitado, tanto nas atividades individuais e/ou coletivas, como nos debates, expondo opiniões, tirando dúvidas, ouvindo os colegas, pedindo dicas, trocando ideias entre eles, entre nós. Alguns debates eram mais acirrados, alguns colegas mais combativos e participativos, outros mais conciliadores e amenos. Tiven seja, nos seus estudos individuais do material de apoio disponibilizado para a formação, mas, no todo nossa primeira etapa do PNEM foi executada do início ao fim com empenho e dedicação, gerando intensas transformações.

Acredito que os objetivos que nos foram colocados no começo desse processo foram alcançados. Mesmo tendo que lidarmos com algumas limitações, como a falta de acesso à internet na Escola, a falta de um espaço exclusivo para as formações, já que não dispomos de nenhuma sala livre para esse tipo de atividade, e as peculiaridades de sermos uma escola pequena, com pouco mais de 450 alunos, com um quadro de professores reduzido, se comparado a outras unidades escolares, inserida em uma comunidade que enfrenta muitas carências, foi possível dialogar sobre nosso Ensino Médio e planejarmos medidas para fortalecê-lo e oferecê-lo com muito mais qualidade e potencialidades.

Dentre as ações que desenvolvemos, destaco as oficinas de história de vida (que foram reproduzidas com os alunos pelos professores diretores de turma), a atividade com as cartas da UNESCO sobre a Educação, a construção de projetos visando um melhor trabalho relacionado aos nossos planos de ensino, ou seja, nosso plano de ação curricular integrada.

Esses projetos foram solicitados após toda uma cuidadosa discussão sobre as DCNEM, interdisciplinaridade, contextualização, o ENEM e suas implicações no Ensino Médio atual, entre outras temáticas, tendo sido requisitado que cada professor elaborasse um projeto contextualizado e interdisciplinar para a sua disciplina. Após os estudos e discussões realizadas, foi solicitado o seguinte: "Elabore um projeto para sua disciplina, delineando ações pedagógicas, interdisciplinares e contextualizadas, que tenham como foco a formação humana integral de nossos alunos, para serem executadas no ano letivo de 2015." Os projetos foram elaborados seguindo o seguinte modelo estrutural: Título, Delimitação temática, Objetivos, Metodologia, Cronograma de atividades, Recursos necessários, Resultados esperados e Referências bibliográficas. Resultaram dessa atividade 14 projetos elaborados por nossos professores. Foram eles: "Jogar e passar - é só tentar" (professora de Biologia), "Agenda ENEM" (Coordenadora Pedagógica), "Cultura corporal do movimento" (professor de Educação Física), "As concepções de leitura e o ensino de Língua Estrangeira Moderna: formação de leitores proficientes em múltiplas linguagens" (professora de Espanhol), "Movimentando o ENEM" (professor de Física), "Mural virtual de atualidades" (professora de Geografia), "A ludicidade no ensino de história: uma nova perspectiva" (professor de História), "O ENEM na seara dos Direitos Humanos" (professora de História), "Aprender matemática é fácil” "(professora de Matemática), "Matemática: assim eu aprendo" (professor de Matemática), "Ler é perigoso!" (professora de Português), "Lendo e escrevendo" (professora de Português), "Caixa de leitura" (professora de Português) e "Química da hora!" (professora de Química). Os estudos e discussões realizados para essa atividade fortaleceram a disposicão e conhecimentos para elaborarmos nossos planos de ensino alicerçados nas dimensões e princípios educativos e pedagógicos das DCNEM. 


\section{Considerações Finais}

A transição do ano letivo de 2014 para o de 2015 na Escola Sales Campos aconteceu de uma forma diferente. Toda a caminhada de formação que o PNEM tinha nos proporcionado ao longo do segundo semestre de 2014 gerou uma série de transformações no fazer pedagógico da Escola. Antes de iniciarmos as aulas de 2015, em nossa Semana Pedagógica, tivemos a oportunidade de, com todo o conhecimento, amadurecimento, zelo e responsabilidades conquistados, nos reunirmos por disciplina, por área e com o conjunto de professores da Escola para estruturarmos planos de ensino interdisciplinares e contextualizados, pensando em um currículo escolar, em uma ação integrada da escola, em um planejamento participativo que iniciasse em nossa escola o redesenho curricular necessário para nosso Ensino Médio, com foco na formação humana integral de nossos estudantes. Uma iniciativa muito tímida e cautelosa, mas foi começo, o primeiro passo dado na caminhada rumo à construção de um Ensino Médio que reconheça as peculiaridades e potencialidades das múltiplas juventudes e professores que encontramos em nossas salas de aula. Caminhada essa que não foi/está sendo trilhada só pela Escola Sales Campos, mas por todos e todas que almejam a efetivação de uma educação pública significativa, emancipatória, valorosa.

Na segunda etapa de desenvolvimento do PNEM no Ceará, realizada de fevereiro a junho de 2015, atuei como Formadora Regional no âmbito da Superintendência das Escolas Estaduais de Fortaleza (SEFOR) e passei a ser responsável pela formação de 32 Orientadores de Estudo de Escolas de duas regionais de Fortaleza. Esses Orientadores, assim como fui na primeira etapa do programa, eram responsáveis pela formação no chão da Escola de seus pares e experimentavam as mesmas e/ou muitas outras experiências de êxitos e transformações em suas Escolas. Na Escola Sales Campos, outra professora, antes cursista, assumiu a função de Orientadora de Estudos nessa segunda etapa do PNEM.

De acordo com Alvarado-Prada et al. (2010, p. 367):

A formação, como um caminho de diversas possibilidades, permite às pessoas que transitam desenvolver-se, construir as relaçoes que as levam a compreender contnuamente seus próprios conhecimentos e os dos outros e associar tudo isso com suas trajetórias de experiências pessoais. Assim, a formação docente é uma contínu caminhada dos profissionais da educação, em cujo caminhar atuam todas as sua dimensões individuais e coletivas de caráter histórico, biopsicossocial, político, cultural, próprias de seres integrais e autores de sua própria formação [...]

Os docentes em exercício constroem novos conhecimentos, ideias e práticas, poi a partir daquilo que ja possuem e sabem que continuam seu desenvolvimento. A construção da formação docente envolve toda a trajetória dos profissionais, suas concepções de vida, de sociedade, de escola, de educação, seus interesses, necessidades, habilidades e também seus medos, dificuldades e limitações. $[\ldots]$

A formação continuada de professores, nesse sentido, passa a ser encarada como uma ferramenta que auxilia os educadores no processo de ensino-aprendizagem de seus alunos, na busca de novos conhecimentos teórico-metodológicos para o desenvolvimento profissional e a transformação de suas práticas pedagógicas. Nesse sentido, a escola, como instituição educacional e como espaçol de formação continuada dos professores, precisa proporcionar recursose tempo para que os educadores possam compreender sua própria realidade institucional, analisá-la e, consequentemente, transformá-la. Assim, será desenvolvido um processo de formação que possibilite melhoria no fazer docente individual e coletivo.
Acreditamos que o percurso formativo do Pacto Nacional pelo Fortalecimento do Ensino Médio na Escola Sales Campos possibilitou esse desenvolvimento, essa construção de novos conhecimentos, ideias e práticas e funcionou (funciona) como uma potente ferramenta que auxiliou (auxilia) os educadores da Escola no processo de ensino-aprendizagem de seus alunos. E as temáticas trabalhadas, os encontros realizados, ocasionaram questionamentos e inquietações quanto ao nosso papel como professor, o papel do nosso aluno e o papel do Ensino Médio de qualidade na construção de uma formação integral para a cidadania.

\section{Referências}

ALVARADO-PRADA, Luis Eduardo et al. Formação continuada de professores: alguns conceito interesses, necessidades e propostas. Rev. Diálogo Educ., Curitiba, v. 10, n. 30, p. 367-387, 2010. BRASIL. Ministério da Educação. Pacto Nacional pelo Ensino Médio: Formação de Professores do Ensino Médio. Documento Orientador Preliminar. Brasília, DF: MEC/SECADI, 2013. Disponível em: <http://pactoensinomedio.mec.gov.br/images/pdf/pacto_fort_ensino_medio.pdf $>$. Acesso em: 30 nov. 2015.

Ministério da Educação. Pacto Nacional pelo Fortalecimento do Ensino Médio. Documento orientador das ações de formação continuada de professores e coordenadores pedagógicos do Ensino 204. Brasilia, DF: MEC/SECADI, 2014a. Disponível em: <http://pactoensinomedio.mec

Câmara dos Deputados. Lei de diretrizes e bases da educação nacional. Lei no 9.394 , de 20 de dezembro de 1996. Brasilia, DF: Edicōoes Câmara, 2015.

Câmara dos Deputados. Plano Nacional de Educação 2014-2024. Lei no 13.005, de 25 de junho de 2014. Brasília, DF: Ediçōes Câmara, 2014b.

Ministério da Educação. Diretrizes Curriculares Nacionais para o Ensino Médio: Resolução

Ministério da Educação. Portaria MEC n. ${ }^{\circ} 1140$, de 22 de novembro de 2013. Institui o Pacto acional pelo Fortalecimento do Ensino Médio União, Brasilia, DF, 25 nov. 2013. Seção 1, p. 24

Ministério da Educação. Resolução MEC/FNDE n.o 51, de 11 de dezembro de 2013. Estabelece criterios e normas para o pagamento de bolsas de estudo e pesquisa aos profissionais participantes da formação continuada no àmbito do Pacto Nacional pelo Fortalecimento do Ensino Médio. Brasilia, DF, 11 dez. 2013

CARVALHO, Ana Maria Pessoa de (Org.). Formação continuada de professores: uma releitura das reas de conteúdo. Editora Cengage Learning: Brasil, 2003.

ESTEVES, Luiz Carlos Gil et al. Estar no papel: cartas dos jovens do ensino médio. Brasília, DF UNESCO; INEP/MEC, 2005.

FALSARELLA, A. M. Formação continuada e prática de sala de aula: os efeitos da formação continuada na atuação do professor. Campinas: Autores Associados, 2004.

IAKIMIU, Vanessa Campos de Lara. O programa ensino médio inovador enquanto programa de indução ao redesenho curricular: pontos e contrapontos. In: ANPED Sul, 10., 2014, Florianópolis. Anais... Florianópolis: UDESC, 2014.

KUENZER, Acacia Zeneida. A formação de professores para o Ensino Médio: velhos problemas novos desafios. Educ. Soc., Campinas, v. 32, n. 116, p. 686-687, 2011. Disponível em: <http://www. edes unicamp br>. Acesso em: 30 nov. 2015.

MOEHLECKE, Sabrina. O ensino médio e as novas diretrizes curriculares nacionais: entre recorrências e novas inquietações. Revista Brasileira de Educação, Rio de Janeiro, v. 17, n. 49, 2012.

IILVA, Ana Maria Costa e. A formação contínua de professores: uma reflexão sobre as práticas e as práticas de reflexão em formação. Educação er Sociedade, Campinas, ano XXI n. 72,2000. 
SILVA, Mônica Ribeiro da; COLONTONIO, Eloise Medice. O princípio educativo do trabalho e as possibilidades da formação unitária no âmbito do Ensino Médio integrado. In: PARANÁ; SEED; DET (Org.). O Ensino Médio Integrado à Educação Profissional: concepções e construções a partir da implantação na rede púbica estadual. Curitiba: SEED, 2008. No prelo. Disponível em: <https:// observatorioensinomedio.files.wordpress.com/2014/02/silva-e-colontonio-o-princc3adpio-educativo-do-trabalho.pdf >. Acesso em: 30 nov. 2015. 